\title{
A IMPORTÂNCIA DA ÉTICA NO ENSINO DA ENFERMAGEM ${ }^{1}$
}

[The importance of Ethics in nursing teaching]

\author{
Amarilis Schiavon Paschoa/* \\ Maria de Fátima Mantovani** \\ Ymiracy N. S. Polak***
}

Resumo: A ética se refere à reflexão crítica sobre o comportamento humano e no ensino de enfermagem a disciplina faz "parar para pensar" a responsabilidade profissional. Este artigo é uma reflexão teórica sobre o ensino dessa disciplina na busca da autonomia, do agir com competência, em mobilizar conhecimentos para julgar e eleger decisões para a prática profissional democrática.

Palavras chaves: Ética de enfermagem; Autonomia profissional.

\section{INTRODUÇÃO}

Refletindo sobre os temas éticos discutidos, como conceitos de ética e bioética, sua importância no ensino, no cuidado e na pesquisa, e identificando-os com minha prática profissional, que é voltada a área educativa, tentarei abordar a questão ética no ensino da enfermagem.

\footnotetext{
${ }^{1}$ Estudo apresentado na disciplina de Ética e bioética em Enfermagem, do curso de Mestrado em Enfermagem da UFPR, ministrada pela Profa Dra Ymiracy N. S. Polak.

*Enfermeira, Pós-graduada em Metodologia do Ensino Superior, diretora do Centro de Educação Profissional Evangélico, Coordenadora do curso de Enfermagem da Faculdade Evangélica do Paraná, mestranda do curso de Mestrado em Enfermagem da UFPR.

**Professora Adjunta do Departamento de Enfermagem da Universidade Federal do Paraná. Doutora em Enfermagem-EEUSP. Coordenadora do Grupo de Estudos Multiprofissional em Saúde do Adulto (GEMSA).

***Doutora em Filosofia da enfermagem, Pós-Doutora em Tecnologia de Comunicação e Informação pelo Instituto de Educação da Universidade de Londres, Professora participante do programa de Mestrado da UFPR, Reitora da Universidade Virtual do Maranhão - UNIVINA.
}

Ao conceituar ética, enquanto disciplina, FORTES (1998) se refere à reflexão crítica sobre o comportamento humano, reflexão que interpreta, discute e problematiza, investiga os valores, princípios e o comportamento moral, à procura do "bom", da "boa vida", do "bem-estar da vida em sociedade". A tarefa da ética é a procura de estabelecimento das razões que justificam o que "deve ser feito", e não o "que pode ser feito". É a procura das razões de fazer ou deixar de fazer algo, de 
aprovar ou desaprovar algo, do que é bom e do que é mau, do justo e do injusto. Fala de motivação, resultados, ações, ideais e valores, princípios e objetivos. A ética pode ser considerada como uma questão de indagações e não de normatização do que é certo e do que é errado.

\section{CONCEPÇÕES DA ÉTICA NO ENSINO DA ENFERMAGEM}

No ensino da enfermagem a ética faz parte do currículo como disciplina, com conteúdos que devem permitir a criação de espaços para a reflexão, com característica de fazer "parar para pensar", objetivando fazer raciocinar adequadamente bem para conduzir com competência, comprometimento e responsabilidade a profissão. A ética pode ser definida como saber que agrega e integra as várias disciplinas do currículo de enfermagem, para que todos tenham uma linguagem comum, relacionada aos princípios éticos que norteiam nossa profissão.

Inseridos no contexto da ética educativa encontram-se vários valores. Nesta situação serão discutidos apenas os valores estéticos e políticos e seus determinantes.

Feitas essas considerações, percebe-se a estética na enfermagem caracterizada pela sensibilidade, que qualifica o fazer humano na medida em que afirma que a prática deve ser sensível a determinados valores.

O primeiro valor a ser descrito é o ideal da profissão, que é a sua valorização, que imprime o respeito, o orgulho e a dignidade daqueles que a praticam. É a busca pela qualidade do serviço e pelo respeito ao cliente que, neste contexto, se insere como a boa assistência prestada, assim como a construção do conhecimento, dentro de uma relação interpessoal imprescindível ao desenvolvimento individual, profissional e social.

Nesta linha de pensamento entende-se a estética da sensibilidade como capacidade profissional que valoriza a diversidade de trabalhos e de clientes, estimula a criatividade e a ousadia, 
qualidades que devem ser desenvolvidas na enfermagem, visando à prestação do cuidado mais humanizado.

A busca de novo paradigma no ensino da enfermagem deve contemplar a estética, porquanto, ao relembrar a história da enfermagem, vimos que foi fundamentada na caridade, religiosidade, intuição e submissão ao saber médico, num desempenho de prática rotineira e mecanicista, em que dificilmente se deparavam sensibilidade e arte.

Ainda hoje a enfermagem é fortemente influenciada pela visão cartesiana de homem, caracterizada pela separação entre corpo e alma, e pelo modelo biologicista, que combate os sintomas e as causas das doenças, sem se preocupar com outros determinantes, como os emocionais, psicológicos e sociais que interferem no estado de saúde e doença das pessoas.

O processo de trabalho em enfermagem também sofre essa influência cartesiana, pois a assistência é fragmentada, a responsabilidade do planejamento e gerenciamento do cuidado é do enfermeiro, e a execução dos procedimentos é realizada pelos técnicos e auxiliares.

Atualmente muitas críticas são feitas ao exercício desta prática delimitada por velhos paradigmas, condicionada ao biologismo e à fragmentação do individuo, mas que ainda é prática dominante.

A tendência em seguir modelos e práticas profissionais deve-se em parte, à insegurança teórica dos profissionais de enfermagem, que tem dificultado a crítica dos paradigmas vigentes e a construção de modelos alternativos (RIZZOTTO, 1999).

Diante disto, há necessidade de fortalecer o enfoque humanístico, nos currículos de enfermagem, valorizando a interdisciplinaridade, formando um profissional atuante, crítico e preparado cientificamente, a fim de poder relacionar teoria e prática em sua ação, o que leva ao desenvolvimento teórico e crítico da profissão. 
A estética está em consonância com o surgimento deste novo paradigma, pois esta mudança traz em sua essência elementos de uma nova sensibilidade para com as questões que envolvem o mundo do trabalho e seus profissionais.

A educação fundamentada na estética da sensibilidade deverá organizar seus currículos de acordo com valores que fomentem a criatividade, a iniciativa e a liberdade de expressão, abrindo espaços para a incorporação de atributos como a leveza, a multiplicidade e o respeito pela vida e intuição. Currículos inspirados na estética da sensibilidade são mais prováveis de contribuir para a formação de profissionais que, além de tecnicamente competentes, percebam na realização de seu trabalho uma forma concreta de cidadania.

Ao pensar em valores políticos dentro do ensino e da prática da enfermagem, entende-se que estes devem levar a uma política da igualdade de condição na aquisição de conhecimentos e na atuação profissional, devendo ser desenvolvidos, com o respeito ao bem comum, à solidariedade e à responsabilidade. Constituem, assim, um compromisso pessoal e social nos indivíduos, com a compreensão de seus direitos e deveres, tanto na educação quanto na saúde.

A política da igualdade deverá incentivar situações de aprendizagem nas quais o protagonismo do aluno e o trabalho de grupo sejam estratégias para a contextualização dos conteúdos curriculares na práxis. Nesse sentido, a política da igualdade está sintonizada com as mudanças na organização do trabalho pelas quais as relações hierarquizadas estão sendo substituídas pela equipe, pelo cuidado, como essência da prática da enfermagem, bem como pelo acolhimento de várias lideranças em lugar do único supervisor, como também pela solidariedade e companheirismo na realização das atividades profissionais.

Os determinantes dos valores estéticos e políticos são as questões éticas que devem partir da autonomia intelectual e da conscientização, construídas na formação da pessoa, que se caracteriza como o fundamento da ética. Ao definir a pessoa como um ser com possibilidades de escolhas e 
constituído de valores, formada por uma rede de relações que começa no seio materno, se amplia na família, na cultura e na política, ao longo de toda a existência, entende-se que a construção das questões éticas se desenvolve num processo de inter-relações.

A ética na educação deve propiciar ao aluno o exercício da escolha e da decisão entre alternativas diferentes, tanto na execução de atividades profissionais como na definição de caminhos, procedimentos ou metodologias mais eficazes para o desenvolvimento com qualidade da sua vida pessoal e social.

A ética deve permear e influenciar permanentemente as condutas dos alunos para fazer deles defensores do valor da competência, do mérito e da capacidade de tudo fazer bem feito, contra favoritismos de qualquer espécie, e levando em conta a importância da recompensa pelo trabalho bem executado, que inclui o respeito, o reconhecimento e a remuneração condigna ( PARECER 16/99, 1999).

Tal contextualização é corroborada, porque, para agir competentemente, é preciso posicionarse diante da situação com autonomia, para produzir o curso de ação mais eficaz. A competência inclui o decidir e agir em situações imprevistas, o que significa intuir, pressentir e arriscar, com base na experiência anterior e no conhecimento.

Ser competente é ser capaz de mobilizar conhecimentos, informações e até mesmo hábitos, para aplicá-los, com capacidade de julgamento, em situações reais e concretas, individualmente e com sua equipe de trabalho. Sem capacidade de julgar, considerar, discernir e prever os resultados de distintas alternativas, eleger e tomar decisões, não há competência. Sem os valores da sensibilidade e da igualdade não há julgamentos ou escolhas autônomas que produzam práticas profissionais para a democracia e a melhoria da vida ( PARECER 16/99,1999).

Sob esta ótica a educação ética deve abordar os seguintes pontos:

- educar para a responsabilidade; o individuo deve arcar com as conseqüências de seus atos; 
- educar para o senso crítico; o individuo deve criticar o que conhece e não se deixar massificar;

- educar para aguçar o sentido da justiça social;

- educar para a partilha com disponibilidade; o individuo deve lutar contra o dar tudo;

- educar para o esforço, lutando pela verdade e pela saúde;

- educar para se personalizar.

$\mathrm{Na}$ educação ética, a consciência, enquanto percepção que as pessoas têm de si, do meio ambiente e dos outros, ocupa lugar de destaque. É o julgamento interno que cada um faz de seus atos e dos atos alheios. Sofre alteração de um grupo profissional para outro, de uma época para outra, pois se baseia em valores que são mutáveis.

\section{CONSIDERAÇÕES FINAIS}

Após discorrer sobre este tema, se obtém com mais clareza o entendimento em relação ao comportamento ético, compreendendo-se os fundamentos da ética, como senso de responsabilidade, a consciência e o conjunto de valores e normas.

Entendendo que a ética pode ajudar-nos a fazer uma escolha, quando reconhecemos nossos próprios valores e normas, refletimos sobre eles, discutimos e examinamos, para ver se são conflitantes ou contraditórios. Assim podemos justificar nossas escolhas éticas de maneira lógica e racional. Os princípios e as normas que procuramos seguir como princípios orientadores devem estar bem determinados na nossa consciência.

A reflexão sob os valores da estética da sensibilidade e dos valores políticos contribuiu para esclarecer nosso pensamento sobre a importância da ética no ensino da enfermagem, visto que entendemos que a formação profissional está nela fundamentada, determinando o perfil profissional desejado, que visa ao desenvolvimento da competência e da autonomia no enfermeiro. 
ABSTRACT: Ethics is concerned with the critical reflection on human behavior and in nursing teaching. This subject is part of the curriculum, enabling to think on professional responsibility. This paper is a theoretical pondering on the teaching of this subject which aims the autonomy in acting competency in order to gather knowledge to judge and make decisions for democratic professional practice.

KEY WORDS: Ethics, nursing; Professional autonomy.

\section{REFERÊNCIAS}

1 FORTES, P.A C. Ética e saúde: questões éticas, deontológicas e legais, tomada de decisões, autonomia e direitos do paciente, estudo de casos. São Paulo: EPU, 1998.

2 PARECER 16/99. Diretrizes curriculares nacionais para a educação profissional de nível técnico. Brasília. Conselho Nacional de Educação. 1999.

3 PESSINI, L., BARCHIFONTAINE, C. P. de. Problemas atuais de bioética. 5. Ed. São Paulo: Edições Loyola, 2000.

4 RIZZOTTO, M. L. F. História da enfermagem e sua relação com a saúde pública. Goiânia: $\mathrm{AB}, 1999$.

5 SILVA, M. A. P. D. da. As representações sociais e as dimensões éticas. Taubaté: Cabral editora universitária, 1998.

6 PEgORARO, O. Ética e bioética. Petrópolis: Vozes, 2000.

Endereço do autor: Rua Odair Pazello, 234 - ap.41 A 81130-080 - Curitiba - PR E-mail: paschoal@onda.com.br 